\title{
Effects of Cathodic Polarization on a Layered Au,Pt-YSZ Mixed-potential Gas Sensing Electrode: Studies by steady- state and dynamic electrochemical methods
}

\author{
X. Zhang ${ }^{1}$, H. Kohler ${ }^{1}$, B. Ojha ${ }^{1}$, U. Guth ${ }^{2}$ \\ 1 Institute for Sensor and Information Systems, Karlsruhe University of Applied Sciences, Moltkestr. \\ 30, D-76133, Karlsruhe, Germany, \\ 2 Faculty of Chemistry and Food Chemistry, Dresden University of Technology, Bergstrasse 66c, \\ D-01062 Dresden, Germany \\ Corresponding author: heinz.kohler@hs-karlsruhe.de (H. Kohler)
}

\begin{abstract}
:
Electrochemical characteristics of a layered Au,Pt-YSZ electrode (APE) were studied by open circuit potential (OCP) and electrochemical impedance spectroscopy (EIS) measurements. The response of the APE to CO was found to be drastically reduced after 100 days operation in ambient air, which is correlated with a clear change in the shape of the EIS characteristics and a considerably increased polarization resistance $\left(R_{p}\right)$. By applying a cathodic polarization, the reduced response can be almost fully restored, and a very similar EIS characteristic as in the initial state is found. This polarization treatment will highly improve stability of the APE and enable applications like flue gas analysis.
\end{abstract}

Key words: Mixed-potential, Au.Pt-YSZ electrode, cathodic polarization, OCP, EIS

\section{Introduction}

Mixed potential (MP) type gas sensors have been extensively studied due to their attractive features in high temperature applications $[1,2]$. In the recent developments, the combination of AuPt-mixtures and zirconia (YSZ) was found to be a promising MP-electrode material. The corresponding sensing responses were found to be strongly related to catalytic properties of the electrode material, which are influenced by the $\mathrm{Au} / \mathrm{Pt}$ ratio and the Au-distribution on $\mathrm{Pt}$ over the electrode layer [1,3].

On the other hand, it was discussed that the catalytic properties and electrode kinetics of a $\mathrm{Pt} / \mathrm{YSZ}$ system are highly affected by formation of $\mathrm{Pt}$ oxide $\left(\mathrm{PtO}_{\mathrm{x}}\right)$. Moreover, it was demonstrated that the formed $\mathrm{PtO}_{\mathrm{x}}$ can be reduced by cathodic polarization [4].

Similar phenomena may probably occur at the AuPt-YSZ MP electrode as well, which are expected to influence the gas sensing behavior. However, these correlations were rarely investigated in the past and therefore motivates the study of the effect of cathodic polarization on an APE by OCP and EIS measurements, especially in relation to its response sensitivity and stability.

\section{Experiment}

A planar sensor comprising an APE on a YSZ layer and a Pt reference (RE) electrode buried beneath (Fig. 1) was studied in this work. The technical details are described elsewhere [3]. The sensor was operated at $600{ }^{\circ} \mathrm{C}$ in ambient dry air for 100 days. OCP responses to $\mathrm{CO}(\Delta \mathrm{U}$ between the APE and the Pt-RE) and EIS behaviors in synthetic air were measured at $600^{\circ} \mathrm{C}$ on the $1^{\text {st }}$ and the $100^{\text {th }}$ day, separately.

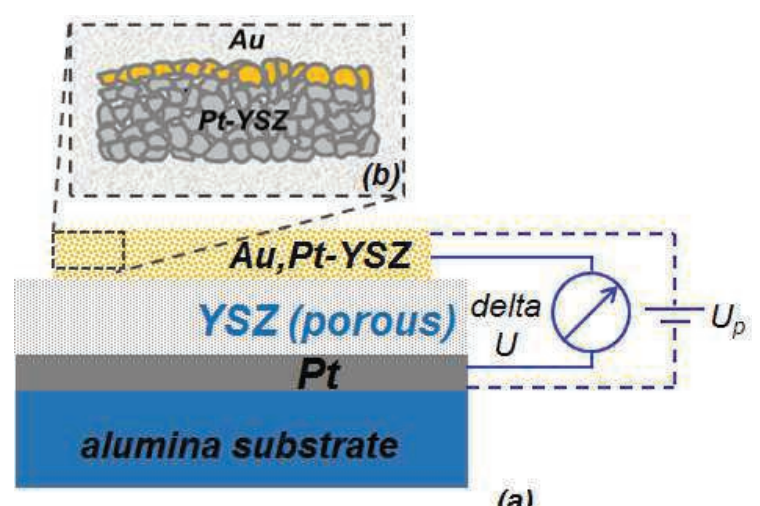

(a)

Fig. 1. Schematic illustration (cross section) of (a) the planar sensor element and (b) layer structure of the $A P E$

Subsequently, cyclic negative potential scans were applied on the APE (Fig. 1 dashed line) at 
$700{ }^{\circ} \mathrm{C}$ in synthetic air, and then the sequence of OCP and EIS measurements was repeated under the same conditions as before. In addition, these electrochemical methods were applied on another individual of this type of sensor, which had been already used for in-situ analysis of the flue gas of a fireplace.

\section{Results and Discussions}

The responses to $\mathrm{CO}$ and the EIS behaviors in synthetic air at $600{ }^{\circ} \mathrm{C}$ at different stages of the experiment are shown in Fig. 2 and Fig 3, respectively. The $\Delta U$ at 1000 ppm $C O$ in air was drastically reduced after 100 days of operation in ambient air, and this is correlated with a slightly positive shift of the baseline in air. But after cathodic polarization of the APE, the $\Delta U$ was almost restored to the initial state (Fig. 2).

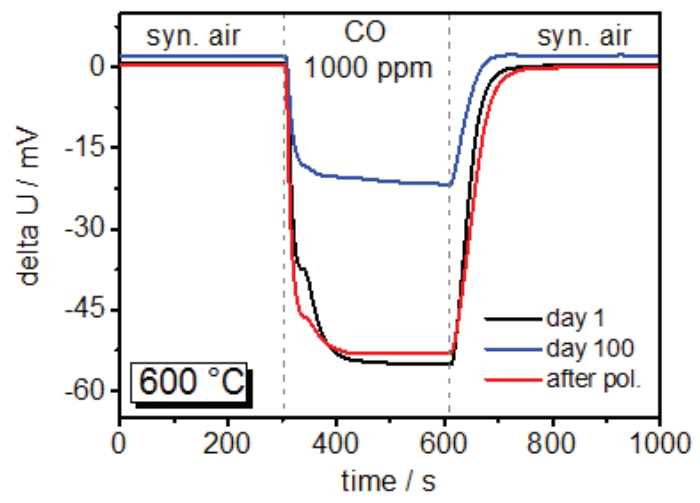

Fig. 2. OCP responses to $\mathrm{CO}$ at $600{ }^{\circ} \mathrm{C}$ on the $1^{\text {st }}$ and $100^{\text {th }}$ day, and after polarization of the APE

These OCP results are well correlated with the EIS data. A clear change in the shape of the EIS characteristic and a considerably increased $R_{p}$ were found after 100 days of operation in ambient air (Fig.3). And an EIS behavior very similar to the initial state (day 1) was measured after polarization.

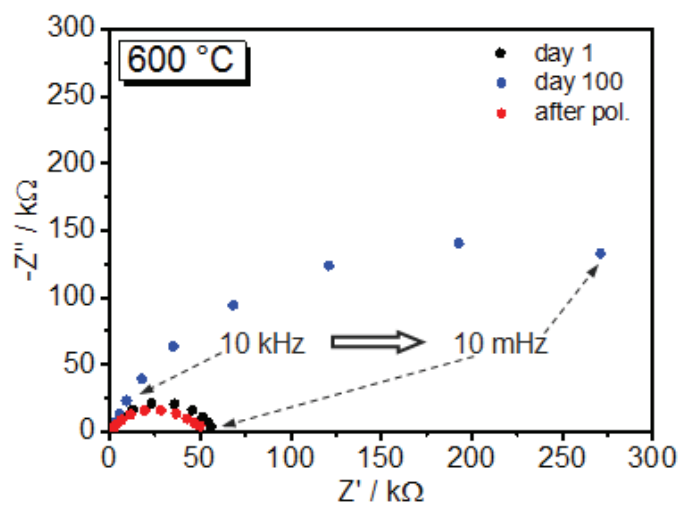

Fig. 3. EIS characteristics in synthetic air at $600{ }^{\circ} \mathrm{C}$ on the $1^{\text {st }}$ and $100^{\text {th }}$ day, and after polarization

According to [4], the increased $R_{p}$ after longterm operation (Fig. 3) indicates the oxidation of the metallic parts of the APE. This would result in a decrease of the concentration of the active electrochemical reaction sites in the potential forming processes, and accordingly depress the MP formation under exposure to $\mathrm{CO}$ and positively shift the baseline in air. These oxidized parts seem to be reduced again to the metallic state by cathodic polarization. As a result, those blocked reaction sites are assumed to be reactivated as well, and accordingly very similar OCP (Fig. 2) and EIS characteristics (Fig. 3) are observed as those before the aging or insitu operation.

The stability of the sensor after operation in the flue gas of wood-log combustion processes was periodically checked in model gases (Fig. 4). After $12 \mathrm{~h}$ of operation, $\Delta \mathrm{U}$ clearly declines, but is raised after cathodic polarization to values even higher than the original ones. It is assumed that EIS and cathodic polarization enable sensitivity evaluation and regeneration of those sensor elements on site of operation. This would be very attractive for implementation of those sensor elements e.g. in advanced combustion air stream control systems for depression of emissions [2].

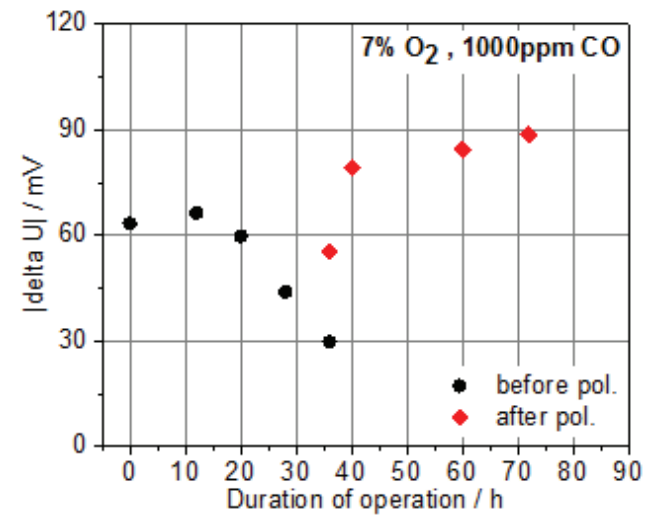

Fig. 4. Response variation of the sensor used in flue gas analysis before and after polarization.

\section{References}

[1] N. Miura, T. Sato, S. Zhuiykov et al. A review of mixed-potential type zirconia-based gas sensors, Ionics 20, 901-925 (2014); doi: 10.1007/s1158

[2] B. Ojha, N. Illyaskutty, H. Kohler et al. Hightemperature $\mathrm{CO} / \mathrm{HC}$ gas sensors to optimize firewood combustion in low-power fireplaces, Journal of Sensors and Sensor Systems 6, 237246 (2017); doi: 10.5194/jsss-6-237-2017

[3] X. Zhang, H. Kohler, U. Guth et al. Mixed potential gas sensor with layered Au, Pt-YSZ electrode: Investigating the sensing mechanism with steady state and dynamic electrochemical methods, Sensors and Actuators B: Chemical 252, 554-560 (2017); doi: 10.1016/j.snb.2017.05.168

[4] H. Pöpke, E. Mutoro, J. Janek et al. The role of platinum oxide in the electrode system $\mathrm{Pt}\left(\mathrm{O}_{2}\right) /$ yttria stabilized zirconia, Electrochimica Acta 56, 10668-10675 (2011): doi: 10.1016/j.electacta.2011.04.057 